\title{
El principio de la simpatía en la Sociología Contemporánea
}

La Sociología contemporánea se caracteriza por haber llamado la atención sobre las sutiles relaciones que se establecen entre los hombres socializados, y que constituyen el mejor elemento de juicio para el investigador de esta nueva ciencia. Hasta hace poco la Sociología se redujo a la descripción más o menos completa de una serie de prácticas y costumbres, sin ahondar el problema hasta las profundidades ónticas de estas relaciones, y eñodondo es únicamente posible encontrar la esencia primordial de la sociedad y de sus elementos.

Por esta escasa capacidad de investigación que se impuso a sí misma la Sociología de principios del siglo XIX, se adjudicó el repudio general de los estudiosos de otras disciplinas, llegando a manifestarse esta tendencia en 1883 en el pensamiento de Wilhelm Dilthey, el mejor teórico de las ciencias del espíritu, quien manifestó que una ciencia se constituye mediante el descubrimiento de verdades importantes, y no apoderándose de un territorio mostrenco en el ancho mundo de los hechos, como lo hacía la Sociología de entonces. Sin embargo, en la segunda edición de su obra fundamental se rectifica ante el avance de la Sociología alemana, para la cual exclama: "mi repudiación a la Sociología no puede referirse a una disciplina semejante, sino que afecta a una ciencia que pretende abarcar en una disciplina única todo aquello que thene de escenario en la sociedad humana".

En efecto, las tendencias modernas de la Sociología se dirigen hacia el análisis minucioso de los elementos fundamentales de la sociedad, que por su misma naturaleza son permanentes, se manifiestan constan- 
temente en determinadas circunstancias y son factibles de una determinación ontológica, dentro de la urdiembre de vinculaciones que hacen irrompible a la sociedad.

Este nuevo punto de vista ha impulsado poderosamente las investigaciones, que haciendo abandono de la vieja escuela evolucionista, solamente preocupada de esquemas generales más o menos comprobados, se ha dedicado al descubrimiento de los principios inmutables que hacen posible la existencia de una serie de instituciones como el Estado, la familia, la propiedad, y que deben resolverse en relaciones primordiales que le sirven de sustento y realidad. Sin una relación de "poder", por ejemplo, el instituto del Estado desaparecería, y aún en sus diferentes formas hasta hoy adoptadas, este sustrato es inmanente a su existencia, así como lo es támbién la "subordinación", fuera de otras relaciones específicas que proporcionan al Estado su verdadera naturaleza. Son estos principios sociales los que deben ser descubiertos y hacia donde debe dirigirse el esfuerzo de la moderna Sociología, para văloţar posteriormente sus diferentes combinaciones y encontrar la "necesidad" de los distintos institutos que son los únicos que se modifican en la sociedad, según la adhesión o ausencia de ciertos elementos fundamentales.

- Un gran paso en este sentido ha sido la admirable investigación llevada a cabo porl el ilustre profesor Max Scheler en el campo de las relaciones de los hombres. Su ebra fundamental a este respecto, "La esencia y las formas de la simpatía (1), publicada en 1923 como sequnda edición corregida de su estudio anterior, de 1913, "Fenomenología. de.los: sentimientos simpáticos", (2). es un campo inmenso de sugerencias y de problemas a resolver, que cautiva al estudioso y enciende nuevas luces en las cuestiones de la sociología moderna.

El propio Scheler, en el prólogo a la tercera edición de su obra, manifiesta que la sociología no puede menos de tener en cuenta los fenómenos de la simpatía, puesto que todas las formas de grupos humanos, empezando por la masa inorganizada y unida por contagio de sentimientos; hasta las más altas organizaciones, están ligadas, además de otras; fuerzas; por estructuras de conducta simpática en cada caso.

La tedría de la simpatía de Scheler se basa en un conocimiento comprensivo e intencional de las vivencias ajenas, puesto que se trata de

(1) Wesen und Formen der Sympathite- Colonia, 1923.

(2) Zur.Phânomenologle und Theorie des Sympathiegefühle und von Liebe und Hass.1913. 
relaciones entre dos o más individuos. Este conocimiento de las vivencias se produce "inmediatamente", sin necesidad de ningún "razonamiento", y tiene - a decir del pensador alemán- la característica de una "percepción originaria". Este contacto con determinadas vivencias se produce por medio de una relación simbólica, pues percibimos la vergüenza en el rubor y en la risa la alegría. Sobre los procesos simbólicos ha insistido tenazmente Ernest Cassirer, en su "Antropología Filosófica", definiendo al hombre no como un animal racional, sino como un animal simbólico y distinguiéndolo de los seres inferiores en el hecho fundamental de que éstos se realcionan por medio de signos, mientras que la humanidad los hace por medio de símbolos. (3). Sin embargo parece que el sentido del símbolo de Scheler se confunde con el del signo de Cassirer, por lo que se hace necesario compulsar nociones a fin de adecuarlas al verdadero sínificado de la realidad.

Hay que distinguir - propone Scheler-cuatro hechos enteramente diversos:

10, "el sentir con otro", que en esencia es sentir no sólo el mismo complejo de valor, sino también el mismo movimiento emocional en dirección a él. Siente uno con otro la misma pena, el "mismo" dolor, pero siempre referido únicamente a un dolor moral, más no a un padecer físico. Por ejemplo, un padre $y$ una madre se identifican en el dolor por la muerte de un hijo, no siendo este dolor objetivo uno para el otro, sino que es el mismo.ge Puccinelli Converson

$2^{\circ}$, el "simpatizar", que implica la intención de sentir dolor o alegría por la vivencia del prójimo. Aquí el dolor de B se hace presente primero en un acto de comprensión, al cual se dirige luego la compasión de A. Mi compadecer y su padecer son fenomenológicamente dos hechos distintos y no uno solo como en el primer caso.

3 , el "contagio afectivo", en donde falta tode geruino fenómeno de simpatía, se produce pura y simplemente entre estados afectivos, y no presupone en general ningún saber de la alegría ajena, ya que puede darse el hecho de descubrir que el sentimiento de tristeza con que uno se encuentra descansa en un contagio procedente de una reunión visitada horas antes. Pero aún todavía no es necesaria la presencia de vivencias ajenas afectivas, sino que puede producirse el contagio de los sentimientos homónimos que se adhieren a los objetos, como la jubilosidad de un paisaje de primavera o la miseria de una habitación. El proceso del contagio tiene lugar involuntariamente.

(3) Ernesł Cassirer.- Antropología Filosófica. México, 1945, p. 68. 
4ㅇ la "genuina unificación afectiva", que es también involuntaria e inconsciente, y se divide en éxtasis momentáneo y éxtasis permanente. El primero se produce por ejemplo cuando el espectador se unifica efectivamente con el actor, cuyos movimientos llevaría a cabo interiormente. El segundo puede durar largo tiempo e incluso hacerse habitual en fases enteras de la vida y presenta dos tipos polares :el idiopático y el heteropático, es decir que la unificación puede producirse absorviendo el yo ajeno en el propio, como ejemplo de la identificación de los miembros de un totem con sendas especiales animales; y puede también suceder que el yo propio sea absorvido por el ajeno, como en el caso del hipnot'smo. Scheler distingue, además, la "fusión mutua", cuya forma más elemental se da en el acto sexual por amor, en el que ambas partes creen sumergirse en un torrente de vida que ya no contiene en sí ninguno de los yos individuales aisladamente, pero que tampoco representa la concienciá de un nosotros fundada sobre el darse el yo por ambas partes.

La unificación afectiva tiene dos características fundamentales, según este notable filósofo alemán: $1^{\circ}$, se produce automáticamente, sin intervención de ningún razonamiento, y $2^{\circ}$, tiene lugar cuando las esferas noéticas del espíritu y de la razón y la esfera corporal de las sensaciones y sentimientos, se foman tacías, tauedando así el hombre propenso a las unificaciones afectivas. CElindividuo es al mismo tiempo "elevado" sobre los estados de su cuerpo, y "desposeído" como ser espiritual. Este vacío de ambas esferas hace que el hombre cuando olvida su dignidad de espíritu se haga más pequeño que un ser de tipo de hombre, y cuando olvida los estados de su cuerpo se haga más grande que un animal que sólo vive y "es" los estados de su cuerpo.

Estas distinciones del cosentir, la compasión, el contagio y la unificación, repectivamente, tienen una especial importancia puesto que han servido para que Max Scheler estructure una serie de consecuencias que forman otras tantas relaciones especiales de los hombres, y que sirven para explicar ciertos aspectos sociológicos que hasta ahora habían pasado desconocidos.

El "sentir lo mismo que otro", explica la crueldad en la cual hay la alegría de atormentar, sintiendo en el crecer del dolor o del pesar de la víctima aumentar el goce del dolor ajeno. Lo propio sucede con la familia cuyas relaciones se fundan en el "sentir lo mismo que otro", al igual que la venganza de la sangre, tan usada en épocas antiguas y aún entre los primitivos peruanos. La relación entre el espectar y la 
acción teatral contemporánea, se funda también en el cosentir, en el sentir el padecer ajeno como propio, y cosa igual puede decirse del cinematógrafo, donde la simulación es más completa. El amor materno, o sea la relāción entre madre e hijo, cuando éste ha salido fuera de su asistencia inmediata, se convierte de unificación afectiva en cosentir. En cambio el amor paterno es desde su origen "sentir lo mismo que otro".

De igual manera la "genuina unificación afectiva" es el fundamento de una serie de prácticas sociales. La forma idopática da origen al totemismo, al culto de los antepasados y es la base de la doctrina de la reencarnación. En cambio la forma heteropática explica los misterios religiosos de la antiguedad, el hipnotismo, la sumisión espontánea del débil al fuerte que antecede como impulso primitivo a los fines de la propia conservación; es el fundamento del màsoquismo, como participación afectiva en la superior actividad del cómplice, es decir, la adquisición simpatética de poder que viene a constituír el objeto del goce. Pero sobre todo, lo más interesante de este principio es la fundamentación del juego infantil, en el cual se produce una verdadera "unificación" como relación entre el niño y sus elementos de juego. Diversas patologías de la conciencia también se explican por este proceso de unificación, como por ejemplo la división de la personalidad. Por fin, la propia conexión entre la madre y el hijo recién nacido tiene esta naturaleza de afectividad, puesto que éste es una parte del ser amante.

La forma de la "fusión minutua" explicae el actor sexual por amor, y sobre todo la danza primitiva y aún el baile contemporáneo que son formas de identificación de los yo individuales sin perder la conciencia del nosotros, dentro de un torrente de vida que bien puede ser el placer vital o la fuerza del ritmo. Pero esta forma aún se da también en la masa inorganizada que se unifica afectivamente con el caudillo, quien otorga a su vez una fusión mutua idiopática de los miembros de la masa entre sí.

Por su parte el "contagio afectivo" también proporciona explicaciones suficientes para el gregarismo animal, la sugestión, la risa contagio$s a$, y aún la opinión púbica que no es sino una reciprocidad del contagio; la multitud que es una masa en acción arrastrada más allá de las intenciones de los individuos; el contagio voluntario, como buscar una fiesta para distraerse; la angustia del contagio que es la ansiedad de esquivar la imagen del dolor; etc. La "compasión", o sea el compadecer el dolor ajeno y sentirlo como ajeno, termina con el contagio, de manera que éste vendría a ser su límite. 
Como se aprecia, el aporte de Max Scheler a la Sociología contemporánea ha sido invalorable, y del estudio detenido de sus principios fundamentales puede desprenderse conclusiones valederas para explicar las más delicadas relaciones entre los hombres socializados, y que permitirá deslindar definitivamente la verdadera naturaleza de lo social y convertir a la Sociología en una ciencia de conocimiento cierto y permanente.

José Mejía Valera. 